\title{
Sustainable Development Research in Chinese Medium-Sized City Based on SLEUTH
}

\author{
Rong Du \\ School of Architecture, Southeast University, Nanjing, China \\ Email: 101008894@seu.edu.cn
}

How to cite this paper: $\mathrm{Du}, \mathrm{R}$. (2020) Sustainable Development Research in Chinese Medium-Sized City Based on SLEUTH. Journal of Environmental Protection, 11, 977-985.

https://doi.org/10.4236/jep.2020.1111061

Received: October 14, 2020

Accepted: November 15, 2020

Published: November 18, 2020

Copyright $\odot 2020$ by author(s) and Scientific Research Publishing Inc. This work is licensed under the Creative Commons Attribution International License (CC BY 4.0).

http://creativecommons.org/licenses/by/4.0/

\section{(c) (i) Open Access}

\begin{abstract}
Compared with megacity, the medium-sized city is playing a more and more important part in the rapid urbanization process in China. Due to the expanding scale of the medium-sized city, urban growth is sprawl and this way leads to ecological, social and environment problems that are unsustainable. To measure the urban growth of the medium sized city, cellular automata (CA) model is employed. CA has proven to be a popular and effective modeling approach to investigate dynamic urban growth systems and for evaluating the impacts of possible policy options. We use the SLEUTH model, which is a well known CA model, to simulate the future urban growth of Huaian, Jiangsu province of China. The results confirm the value of SLEUTH which provides a rich exploratory of knowledge for evaluating the effects of possible decision-making in local government.
\end{abstract}

\section{Keywords}

Urban Growth, Cellular Automata, SLEUTH, Medium-Sized City, Huaian

\section{Introduction}

In the twenty-first century, the large cities of China are confronted with great challenges of environment and development inevitably. The pressure of three kinds of population peaks which are the total population, the employed population and the aging population, extraordinary use of natural resources, progressive deterioration of ecological environment, have become bottlenecks for sustainable city development. The National Ministry of Science and Technology of China decided to explore the coordinated development model of population, environment and resources in the process of Industrialization and Urbanization in the medium-sized and small-sized cities, which make up 56 percent of the city's total, in 1986. The medium-sized city is playing a more and more important part 
in the rapid urbanization process in China [1].

Sustainable city is a new model of city development. There remains no completely agreed upon definition for what a sustainable city should be or completely agreed upon paradigm for what components should be included. Generally, developmental experts agree that a sustainable city should meet the needs of the present without sacrificing the ability of future generations to meet their own needs. The ambiguity within this idea leads to a great deal of variation in terms of how cities carry out their attempts to become sustainable [2]. A useful way to clarify its ambiguity is to set up some quantitative indicators. Unlike the western country, the urban planning of the Chinese local government is significant for the city development in China. In this paper, we focus on two of the most pressing issues that are directly affected by the urban form: management of urban planning and the conversion of surrounding agriculture and natural land.

Cellular automata model provide an effective and somewhat neutral as well as generic representational framework for the study of land use change and urban growth [3] [4]. Since urban growth occurs in time and space, disaggregate and dynamic modeling approaches provide a useful knowledge base for understanding the urban growth process and signature spatial patterns that represent their outcomes. SLEUTH is a well known urban cellular automata model. The name SLEUTH was derived from the simple image input requirements of the models: Slope, Land cover, Exclusion, Urbanization, Transportation, and Hillshade. We will demonstrate the urban growth by applying SLEUTH to the Huaian, north of Jiangsu province, China. According to the definition of China, cities are divided into five categories: municipalities directly under the central government; special economic cities; coastal cities open to the world; economic development cities and other cities. Huaian which belongs to the economic development cities is a medium-sized city undergoing rapid physical growth and change of land covers and uses. The purpose of our presentation is twofold: to explore the methodological implication of what the model can predict for these regions through such empirical applications, and to assess if the presented scenarios which present the possible consequences of different planning options are sustainable.

\section{Method}

Modeling is essential for the analysis, and especially for the prediction, of the dynamics of the urban growth [3] [4]. To model urbanization across locales, it is just as important to test the efficacy of the model's algorithms at capturing and simulating the land transformation that is specific to a place [5] [6].

\subsection{Overview of SLEUTH}

The SLEUTH urban growth and land use change model is a cellular automaton (CA) model that has been widely used to model urbanization throughout various regions of the United States and the world [3] [4] [5]. SLEUTH is an acronym for the input layers that the model uses in gridded map form: Slope, 
Land Use, Exclusion, Urban Extent, Transportation and Hillshade. The basic growth procedure in SLEUTH is a cellular automaton, in which urban expansion is modeled in a spatial two-dimensional grid. Diffusion, breed, spread, slope and road coefficients control the behavior of the cellular automaton, and four types of growth behavior can take place: spontaneous, diffusive, organic and road-influenced. Self-modification of the rules changes the control parameters when modeled growth rates are exceeded, so that the model's behavior includes feedback [3]. In cellular automata simulating artificial life, self-modification is equivalent to adaptation or evolution, and the calibration method used allows the model to "learn" its local setting over time [6].

\subsection{Running and Calibration}

By running the model, a set of control parameters is refined in the sequential calibration phase (coarse, fine and final calibrations). Between phases in the calibration, the values that best match the five factors could be extracted: diffusion (overall scatter of the growth), breed (likelihood of new settlements being generated), spread (growth outward and inward from existing spreading centers), slope resistance (flat ground is preferred) and road gravity (attraction of urbanization to roads and diffusion of urbanization along roads). Coefficient combinations result in combinations of the 13 metrics: each either the coefficient of determination of fit between actual and predicted values for the pattern (such as number of pixels, number of edges, number of clusters), for spatial metrics such as shape measures, or for specific targets, such as the correspondence of land use and closeness to the final urban pixel count [3] [7].

Five coefficients (with values 0 to 100) control the behavior of the system, and are predetermined by the user at the onset of every model run. These parameters are [7] [8] [9] [10] [11]:

- Diffusion-Determines the overall dispersiveness nature of the outward distribution.

- Breed Coefficient-The likelihood that a newly generated detached settlement will start on its own growth cycle.

- Spread Coefficient-Controls how much contagion diffusion radiates from existing settlements.

- Slope Resistance Factor-Influences the likelihood of development on steep slopes.

- Road Gravity Factor-An attraction factor that draws new settlements towards and along roads.

SLEUTH also has a "self-modification" function, which is intended to more realistically simulate different rates of growth over time [3] [12]. When the rate of growth exceeds a specified critical threshold, the growth coefficients are multiplied by a factor greater than one, simulating a development "boom" cycle. Likewise, when the rate of development falls below a specified critical threshold, the growth coefficients are multiplied by a factor less than one, simulating a de- 
velopment "bust" cycle.

\section{Study Case}

The city of Huaian is located in the north-central part of Jiangsu province [13]. It has a population of 5,230,000, an area of $100.72 \mathrm{~km}^{2}$ (urban area) in 2020. It is characterized by dispersed rivers and lakes. The Salt River, ancient Yellow River, Li Canal and the Grand Canal flow through the urban area from west to east, forming the distinctive urban pattern. In the early time, the city was developed slowly, and residents were mainly concentrated along the Li Canal. The construction of highways from Beijing to Shanghai promoted urban expansion rapidly in 2000 , and the regional plan made by the local government integrated the surrounding four counties into the city in 2001, that organized the city area with housing, industry, tourism.

\subsection{Data Source}

The data source for the city of Huaian database involved a variety of sources, including Landsat imagery, historical maps, master plans of Huaian city [13] and reports. We set three different spatial resolutions of cells $(120 \times 120 \mathrm{~m}, 60 \times 60$ $\mathrm{m}, 24 \times 24 \mathrm{~m}$ ) for testing spatial sensitivity of model. Maps with cells of the above three different resolutions for urbanization, roads, excluded areas, topographic slope, and a hillshaded backdrop were created in the ArcGIS and converted into the 8-bit GIF format used by the SLEUTH Model. Table 1 and Figure 1 show the input data for SLEUTH.

Table 1. Input data for SLEUTH.

\section{Data Layer Data}

Urban extent data Urban boundary in 1982, 1995, 2000, 2015 data classified from Landsat imagery

Land use data Land use status in 1982, 1995, 2000, 2015 data classified from Landsat imagery

Road data $\quad$ Road status in 1982, 1995, 2000, 2015 data classified from Landsat imagery

Excluded data Watershed and open park areas that are resistant to urbanization Prohibited and restricted construction areas in Master planning of Huaian (2009-2030)

Slope data DEM

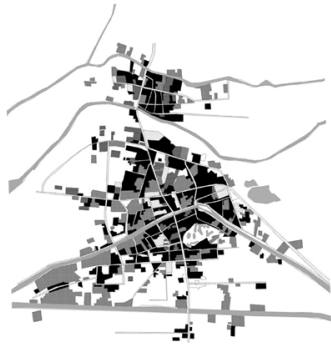

1982 Urbanization of Huaian

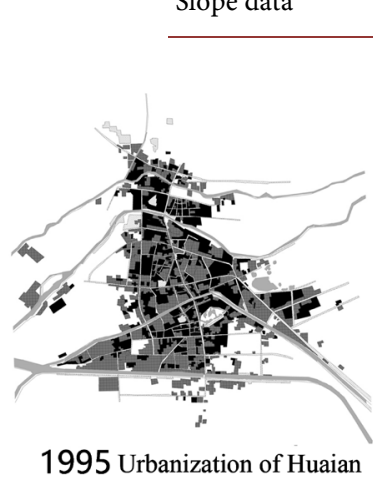

1995 Urbanization of Huaian

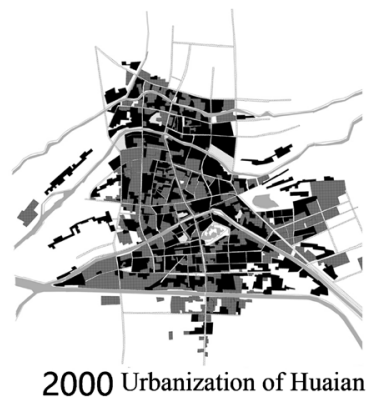

2000 Urbanization of Huaian

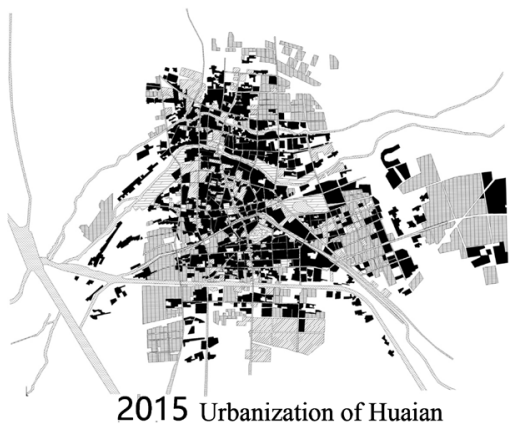

2015 Urbanization of Huaian

Figure 1. Input land use data for SLEUTH. 


\subsection{Results}

All data processing was accomplished in ArcGIS 10.0, and vector coverage was converted to raster format. Three spatial resolutions with $120 \mathrm{~m}, 60 \mathrm{~m}$, and $24 \mathrm{~m}$ were completed for Huaian city using SLEUTH. In these data, two calibrations and forecasts of urbanization and land use change were completed for Huaian city. The first calibration and forecast used all of the data, aggregating the land use data into urban/non-urban, and the second, the data was disaggregated into six land use categories. The result of calibration applied to Huaian city is presented in Table 2. It shows as follows:

- Model performance in city areas was improved with increased spatial and parameter resolution. The five coefficients presented in Table 3 were narrowed down to reflect the city area accurately. The sensitivity of spatial resolutions to local conditions will be explored in the next section.

- Due to the limitation of the surrounding river and watershed, the growth rate of the city has slowed down significantly after 2020. The rate of growth falls below the critical threshold of self-modification function and the system begin to simulate the "bust" cycle for the urban growth.

- The result shows the simulation of multiple land use categories is not sensitive to the growth rate, that means the growth of city is reflected in the boundary of city. The increase in land use within city is not reflected in the results. A composite metric that was the product of the compare, population, Lee-Sallee, and F-match statistics was used in simulation. The F-match statistic was used because it evaluates the replication of land use transitional patterns. This metric was required when doing any modeling that includes more

Table 2. Data calibration from 1982-2015.

\begin{tabular}{|c|c|c|c|c|c|c|c|c|c|}
\hline \multirow{2}{*}{ Coefficients } & \multicolumn{9}{|c|}{ Calibration } \\
\hline & \multicolumn{3}{|c|}{ Coarse } & \multicolumn{3}{|c|}{ fine } & \multicolumn{3}{|c|}{ final } \\
\hline \multirow{2}{*}{$\begin{array}{c}\text { Spatial } \\
\text { resolution }\end{array}$} & \multicolumn{3}{|c|}{$120 \mathrm{~m} \times 120 \mathrm{~m}$} & \multicolumn{3}{|c|}{$120 \mathrm{~m} \times 120 \mathrm{~m}$} & \multicolumn{3}{|c|}{$60 \mathrm{~m} \times 60 \mathrm{~m}$} \\
\hline & range & steps & metrics & range & steps & metrics & range & steps & Metrics \\
\hline Diffusion & $1-100$ & 25 & \multirow{4}{*}{$\begin{array}{c}\text { Compare }=0.730 \\
\text { Population }=0.920 \\
\text { Lee-Salle }=0.509\end{array}$} & $1-25$ & 5 & & $1-1$ & 1 & \multirow{5}{*}{$\begin{array}{c}\text { Compare }=0.521 \\
\text { Population }=0.927 \\
\text { Lee-Salle }=0.484\end{array}$} \\
\hline Bread & $1-100$ & 25 & & $1-25$ & 5 & Compare $=0.785$ & $1-1$ & 1 & \\
\hline Spread & $1-100$ & 25 & & $75-100$ & 5 & Population $=0.913$ & $75-75$ & 1 & \\
\hline Slope & $1-100$ & 25 & & $25-100$ & 15 & Lee-Salle $=0.508$ & $40-70$ & 6 & \\
\hline Road gravity & $1-100$ & 25 & & $50-100$ & 10 & & $50-80$ & 5 & \\
\hline
\end{tabular}

Table 3. Coefficients results.

\begin{tabular}{lcccc}
\hline $\begin{array}{l}\text { Coefficients results } \\
\text { Monte carlo iterations: } 100\end{array}$ & & & \\
\hline Diffusion & Breed & Spread & Slope & Road gravity \\
\hline 1.13 & 1.13 & 84.51 & 21.88 & 51.81 \\
\hline
\end{tabular}


detail that urban/non-urban, since it is the only metric that measures the models goodness of fit from the multiple categories in the data [14]. Table 4 shows the compare data between the urban/non-urban data and the multiple land use categories data.

- In order to protect the ecological environment and natural environment, Master planning of Huaian (2009-2030) has designated areas where construction is prohibited, restricted and suitable for construction. The excluded data that generated from the designated area restricts the development of urban growth in the simulation. The forecasting results show that the urban land area will be $180 \mathrm{~km}^{2}$ in 2040 (shown in Figure 2). And the urban land area will be $298 \mathrm{~km}^{2}$ if there are no restricted areas for simulation. The effects of urban planning are obvious for the local government.

\section{Discussion}

\subsection{Sensitivity Testing}

The sensitivity testing can improve the performance of the model and increase the confidence of its results [15] [16] [17]. Huaian was used to exam the sensitivity of calibration process to scaling. Three different spatial resolutions of cells $(120 \times 120 \mathrm{~m}, 60 \times 60 \mathrm{~m}, 24 \times 24 \mathrm{~m})$ are tested for research of spatial sensitivity of model. It was found that different spatial resolutions of cells not only affected the behavior of growth, but also the analysis results. Fine spatial resolution is sensitive to landscape elements, while the coarse spatial resolution is more sensitive to

Table 4. Compare data between the urban/non-urban and multiple land use categories data.

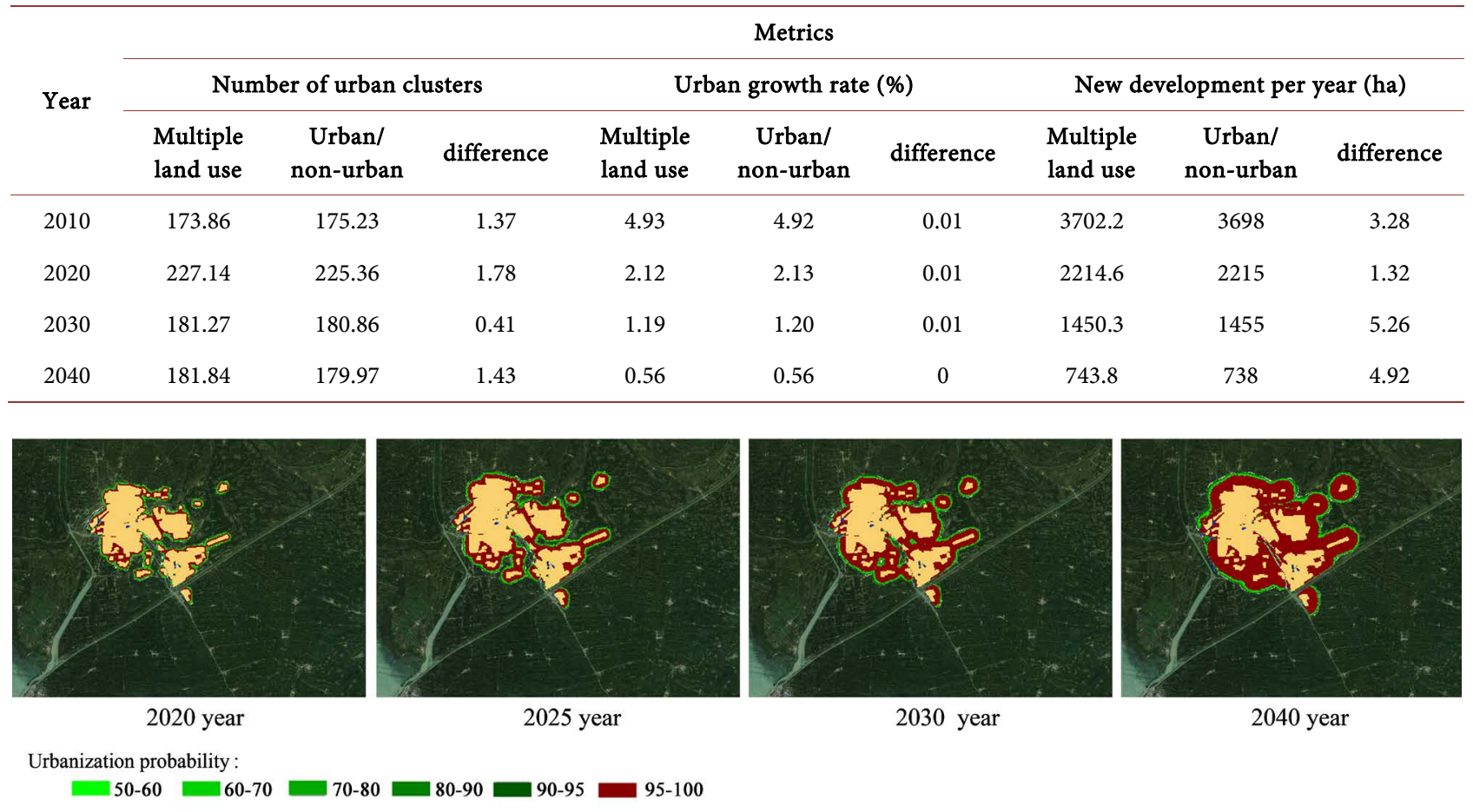

Figure 2. Simulated urban form from SLEUTH. 
environment. The test result of best-fit statistics for metrics shows that spatial resolution with $120 \times 120 \mathrm{~m}$ can reach 0.51 in the coarse calibration, while spatial resolution with $24 \times 24 \mathrm{~m}$ is 0.45 in the same calibration phase. Table 5 shows the detail results of sensitivity test with three spatial resolutions of cells. And the results proved that spatial resolution of cells is sensitive to SLEUTH.

\subsection{Difference between China and Western Countries}

In China, the local government changes its leadership every few years. The new leader often adopts different urban development strategies. Different strategies, policies and measures take effect during different periods of city construction, which leads to urban development lacks consistency. In the simulation, the metric to evaluate the goodness of fit is not high. In the study area of Huaian, the value of Lee-Sallee is 0.5 , which shows that the characteristic of urban space development is leap development. There is a significant change of urban form between the years 2005-2010. In order to accommodate the relocation of industrial areas within the city, the local government had set up new industrial areas in the urban fringe areas, resulting in a significant change in the urban form. The urban development strategy is different from the self-organized development strategy of cities in western countries, that planning to some degree is a

Table 5. Results of sensitivity test with three spatial resolution of cells.

\begin{tabular}{|c|c|c|c|c|c|c|c|c|}
\hline \multirow{2}{*}{ Spatial resolution } & \multicolumn{4}{|c|}{ Best-fit metrics } & \multicolumn{4}{|c|}{ Coefficients } \\
\hline & Compare & Population & Edge & Lee-Sallee & Diffusion & Breed & Spread & Road gravity \\
\hline
\end{tabular}

Total number of simulation $=3127$

Monte Carlo iterations $=7$

\section{A: Compare}

$120 \times 120$

$60 \times 60$

$24 \times 24$

B: Population

$120 \times 120$

$60 \times 60$

$24 \times 24$

C: Edge

$120 \times 120$

$60 \times 60$

$24 \times 24$

D: Lee-Sallee

$$
1
$$

1$$
1
$$

\subsection{0}

$$
0.68
$$$$
0.68
$$

$$
0.34
$$$$
0.28
$$$$
0.22
$$

$$
0.89
$$$$
0.98
$$$$
1
$$

1

$$
0.96
$$$$
1
$$$$
1
$$$$
0.83
$$$$
0.83
$$$$
0.88
$$

$$
0.49
$$$$
0.79
$$$$
0.81
$$

$$
\begin{aligned}
& 0.33 \\
& 0.43
\end{aligned}
$$$$
0.35
$$

1

$1-25$

1

$25-100$

$1-75$

$75-100$

$25-100$

$75-100$

75

$75-100$

(

25

$25-50$

$25-100$

\begin{tabular}{lllllllll}
$120 \times 120$ & 0.73 & 0.92 & 0.50 & 0.51 & 1 & 1 & 75 & $75-100$ \\
$60 \times 60$ & 0.56 & 0.93 & 0.76 & 0.49 & 1 & 1 & 100 & $25-100$ \\
$24 \times 24$ & 0.44 & 0.93 & 0.80 & 0.45 & 1 & 1 & 100 & $25-100$ \\
\hline
\end{tabular}


management of economic market.

The compact city concept is adopted in many western countries because it can promote efficient use of land, reduction in transport networks, a socially interactive environment with vibrant activities, economic viability, and so on. While in China, the urban planning or land use planning is the main tool to affect the urban growth. The central planning practice is beneficial to the sustainable development of city.

\section{Conclusions}

Land-development scenarios as a means of representing the future have been in the planner's toolkit for several decades. The SLEUTH model is an effective decision-support tool to analyze and compare the effects of alternative policies, the range of potential choices of land-use plans. It provides a basis for consideration of different assumptions for the local government concerning land-development futures. However, the simulation is also subject to some certain limitations. The first is that the spatial resolution of cell is sensitive to the simulation system. We need to assess the suitable cell for simulation in order to get the better fit of metrics. In the case of Huaian, we tested three different spatial resolutions of cells for simulation. The result shows $120 \mathrm{~m} \times 120 \mathrm{~m}$ is the most suitable spatial resolution of cell. The second is that simulation is not sensitive for the multiple land use categories. The result does not show much difference between aggregating (urban/non-urban) and multiple land use categories (six land use categories). The last limitation is that it cannot simulate the process of displacement, shrinkage, and disappearance of land, which are common features of urban growth of China.

In short, urban growth and land use change are dynamic spatio-temporal processes, and spatial models of urban growth have the ability to play an important role in the planning process.

\section{Acknowledgements}

This study is supported by the National Natural Science Foundation of China (No. 51878144, No. 6501008008).

\section{Conflicts of Interest}

The author declares no conflicts of interest regarding the publication of this paper.

\section{References}

[1] Jenks, M., Burton, E. and Williams, K. (1996) The Compact City and Sustainable. In: Jenks, M., Burton, E. and Williams, K., Eds., The Compact City: A Sustainable Urban Form, E\&FN SPON, London, 3.

[2] Stanislav, E.S. and Irina, A.S. (2009) Sustainable Cities: Problems of Integrated Interdisciplinary Research. International Journal of Sustainable Development, 12, 4-23. https://doi.org/10.1504/IJSD.2009.027526 
[3] Clarke, K.C., Hoppen, S. and Gaydos, L. (1997) A Self-Modifying Cellular Automaton Model of Historical Urbanization in the San Francisco Bay Area. Environment and Planning B, 24, 247-261. https://doi.org/10.1068/b240247

[4] Silva, E.A. and Clarke, K.C. (2002) Calibration of the SLEUTH Urban Growth Model for Lisbon and Porto, Portugal. Computers, Environment and Urban Systems, 26, 525-552. https://doi.org/10.1016/S0198-9715(01)00014-X

[5] Batty, M. and Xie, Y.C. (1994) From Cells to Cities. Environment and Planning B, 21, 31-48. https://doi.org/10.1068/b21S031

[6] Li, X. and Yeh, A. (2000) Modeling Sustainable Urban Development by the Integration of Constrained Cellular Automata and GIS. International Journal of Geographical Information Science, 14, 131-152. https://doi.org/10.1080/136588100240886

[7] Jantz, C.A., Goetz, S.J. and Shelley, M.K. (2004) Using the SLEUTH Urban Growth Model to Simulate the Impacts of Future Policy Scenarios on Urban Land Use in the Baltimore/Washington Metropolitan Area. Environment and Planning B, 31, 251-271. https://doi.org/10.1068/b2983

[8] Clarke, K., Hoppen, S. and Gaydos, L. (1996) Methods and Techniques for Rigorous Calibration of Cellular Automaton Model of Urban Growth. Third International Conferencel Workshop on Integrating GIS and Environmental Modeling, Santa Fe, 21-25 January 1996, 1319-1328.

[9] Clarke, K. and Gaydos, L. (1998) Loose-Coupling a Cellular Automaton Model and GIS: Long-Term Urban Growth Prediction for San Francisco and Washington/Baltimore. International Journal of Geographical Information Science, 12, 699-714. https://doi.org/10.1080/136588198241617

[10] Dietzel, C.K. and Clarke, K.C. (2004) Spatial Differences in Multi-Resolution Urban Automata Modeling. Transactions in GIS, 8, 479-492. https://doi.org/10.1111/j.1467-9671.2004.00197.x

[11] Yang, X. and Lo, C.P. (2003) Modelling Urban Growth and Landscape Change in the Atlanta Metropolitan Area. International Journal of Geographical Information Science, 17, 463-488. https://doi.org/10.1080/1365881031000086965

[12] Jantz, C.A., Goetz, S.J., Donato, D. and Claggett, P. (2010) Designing and Implementing a Regional Urban Modeling System Using the SLEUTH Cellular Urban Model. Computers, Environment and Urban Systems, 34, 1-16. https://doi.org/10.1016/j.compenvurbsys.2009.08.003

[13] Huaian Editorial Board (2012) Huaian. Contemporary China Publishing House, Beijing.

[14] Dietzel, C. and Clarke, K. (2006) The Effect of Disaggregating Land Use Categories in Cellular Automata during Model Calibration and Forcasting. Computers, Environment and Urban Systems, 30, 78-101. https://doi.org/10.1016/j.compenvurbsys.2005.04.001

[15] Chaudhuri, G. and Clarke, K.C. (2013) The SLEUTH Land Use Change Model: A Review. The International Journal of Environmental Resources Research, 1, 89-104.

[16] Candau, J.C. (2002) Temporal Calibration Sensitivity of the SLEUTH Urban Growth Model. M.A. Thesis, University of California, Santa Barbara.

[17] Rong, D. (2012) Urban Growth: Changes, Management, and Problems in Large Cities of Southeast China. Frontiers of Architectural Research, 5, 290-300.

https://doi.org/10.1016/j.foar.2016.04.002 